\title{
Inheritance of idiopathic torsion dystonia among Jews
}

\author{
NELLY ZILBER*†, AMOS D KORCZYN*‡ ESTHER KAHANA*\$, \\ KALMAN FRIEDII, AND MILTON ALTER*ף \\ From * the Uri Leibowitz Neuroepidemiology Unit, Department of Neurology, \\ Hadassah University Hospital, Jerusalem; $†$ Department of Social Medicine, Hebrew University-Hadassah \\ School of Public Health and Community Medicine, Jerusalem; $\ddagger$ Department of Physiology and Pharma- \\ cology, Tel Aviv University, and Department of Neurology, Ichilov Hospital, Tel Aviv; \\ $\$$ Neurology Section, Barzilai Medical Center, Ashkelon; \\ IIDepartment of Genetics, Assaf Harofeh Hospital, Tel Aviv, Israel; and \\ $\uparrow$ Department of Neurology, Temple University Hospital, Philadelphia, Pennsylvania, USA.
}

SUMMARY Idiopathic torsion dystonia (ITD) has long been considered to be genetically determined, but the pattern of inheritance has been unclear. It has been suggested that inheritance may differ in Jews and non-Jews. In the present study, data gathered in a nationwide survey of ITD in Israel were analysed. Between 1969 and 1980, 47 patients were collected, of whom 40 were of European origin. In these European Jews, the ITD frequency was about 1:23000 live births, which was five-fold greater than in Jews of Afro-Asian origin. Assuming that all cases fit the same genetic model, an $\mathrm{X}$ linked or a simple autosomal recessive model of inheritance did not agree well with our data. An autosomal dominant model with low penetrance could have accounted for our observations and would yield an ITD gene frequency in European Jews of 3 to 4:100 000. In view of the increased ages of their fathers, the isolated cases may have included some new mutations. Multifactorial inheritance was also possible. However, it may be inappropriate to assume that all cases have the same genetic basis, or even that all are inherited.

Idiopathic torsion dystonia (also known as dystonia musculorum deformans) has long been considered to be genetically transmitted, although a significant proportion of subjects are isolated cases. The pattern of inheritance has been unclear. Johnson et $a l^{1}{ }^{1}$ Larsson and Sjögren, ${ }^{2}$ and Zeman and Dyken, ${ }^{3}$ for instance, claimed that inheritance is dominant. Eldridge et $\mathrm{al}^{4-6}$ concluded that two types of idiopathic torsion dystonia (ITD) exist. In one type, allegedly limited to Jews, limbs are affected before axial muscles, onset occurs early in life, and the inheritance pattern is recessive, while the other type is seen in non-Jews, affects axial muscles first, starts later in life, and is inherited as a dominant trait. In 1976, Eldridge and Gottlieb ${ }^{7}$ acknowledged that non-Jews with ITD might also show a recessive form of inheritance and Jews a dominant one. In 1979, Eldridge and Koerber ${ }^{8}$ suggested that all Jewish cases, in fact, had an autosomal recessive pattern,

Received for publication 18 May 1983. Accepted for publication 16 June 1983. but quasidominance** accounted for the occurrence of ITD in successive generations. The conclusions of Eldridge and associates were not based on any quantitative analysis. Moreover, their case material may have been biased. Therefore we have reviewed their conclusions. ${ }^{9}$

We recently conducted a nationwide study of ITD in Israel. ${ }^{10} 11$ As the entire population was studied, selection bias was minimal. Moreover, detailed demographic data were available. Therefore, we could analyse the mode of transmission of ITD in Jews in the Israeli population with greater precision than had been possible previously.

\section{Methods}

The method used for case finding has been described before. ${ }^{10}{ }^{11}$ In 1975 , a study of torsion dystonia in the Israeli population was started. As a first step,

**QQuasidominance refers to a situation where an affected offspring inherits one defective gene from a heterozygous (carrier) parent and 
diagnostic criteria were formulated. To be considered a firm case of torsion dystonia, a patient had to have dystonic posturing or movement and a progression in the abnormality at some time during the course of illness. The perinatal history had to be devoid of abnormalities such as asphyxia or jaundice, and subsequent history could include no bout of encephalitis or trauma which might have produced dystonia. Metabolic disorders such as Wilson's disease or calcium abnormalities had to be specifically excluded. Patients with focal or segmental dystonia (for example, graphospasm alone) were accepted only as a separate subgroup, as were patients who had only torticollis. Where available records were insufficient to establish a diagnosis, the patient was re-examined.

Patients fulfilling the diagnostic criteria were interviewed to establish their pedigree. We specifically asked for the dates and places of birth of forebears, descendants, and collaterals, as well as dates and causes of death and parental consanguinity. We also inquired about abnormalities in posture and movement among relatives; available relatives were personally interviewed and examined.

The Jewish patients were divided into those whose families originated in Europe or America and those whose families originated in Africa or Asia. This division corresponds, in general, to Ashkenazi and Sephardi (or Mizrachi) ethnic groups, respectively. One patient born in Yugoslavia and another born in Spain, and thus included in the 'European' group in this study, were of Sephardic ethnic origin. No 'mixed' family was ascertained.

In order to compute frequency of ITD, the number of Israeli-born ITD patients identified in this study was related to the number of live births in Israel during the period corresponding to the patients' birth. The number of live births was available from 1949 onward by birth place of parents. ${ }^{12}$

\section{Results}

In 1980, we reported 42 patients with ITD in Israel. ${ }^{11}$ Continued medical surveillance of the Israeli population, more recent additions to the National Neurological Disease Register, and reports from physicians enabled us to find an additional seven cases. However, on follow-up, one patient developed seizures and a CT scan revealed unilateral ventricular enlargement, and another became psychotic. These two were excluded from the present study, leaving 47 cases.

The year of onset of ITD in these 47 ranged from 1933 to 1974 . There were nine patients with onset between 1933 and 1950, an average of 0.5 new case per year. Four of these nine belonged to families with several cases and were identified from interviews with probands. There were 38 patients with onset from 1951 to 1975 , an average of 1.5 new cases per year. Patients with onset in the earlier period were, of necessity, older when ascertained and more likely to have died before the survey period.

Among the 47 patients, one was a female Druze Arab. Non-Jews constitute about $14 \%$ of the Israeli population. Six patients were Jews of Afro-Asian origin while half the population of Israel is composed of Afro-Asian Jews. Forty patients were Jews with European forebears though less than half of Israel's population is of European Jewish ancestry. The concentration of ITD among European Jews, regardless of whether they were born in Europe or Israel, favours genetic transmission of the disorder even though many patients seemed to be 'isolated' cases. Complete pedigree data were obtained on 41 of the 47 cases (36 of the 40 of European origin).
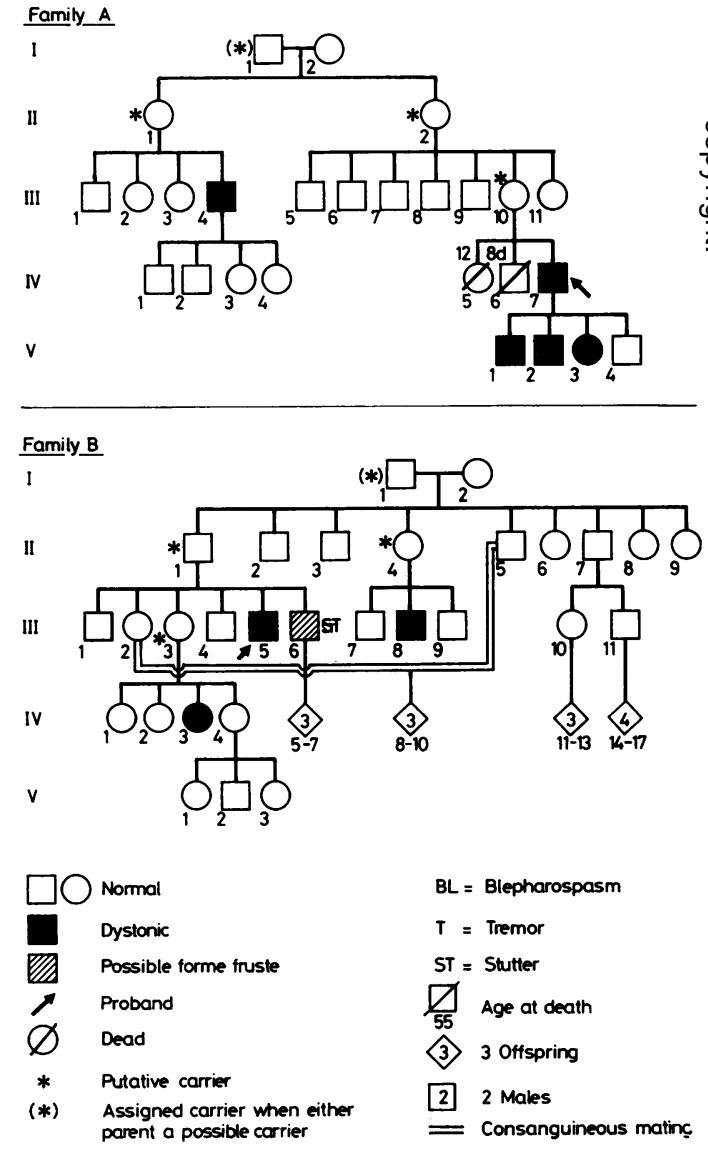
There were four families, all of European origin, with more than one affected subject, hereafter referred to as 'familial cases' (figure, families A-D). These families accounted for 14 cases of ITD.

FREQUENCY OF THE DISEASE

Nineteen of the 47 patients were born in Israel. Since data on live births were available only from
1949, seven of these patients born before 1949 could not be used to calculate incidence. Only one patient in our series was born after 1959. The median age of onset in our series was 12 years. Therefore, persons born in recent years who bear the trait would not be expected to manifest it until they are older. Consequently, frequency of ITD was calculated only for the period 1949 to 1959 and was based on the two
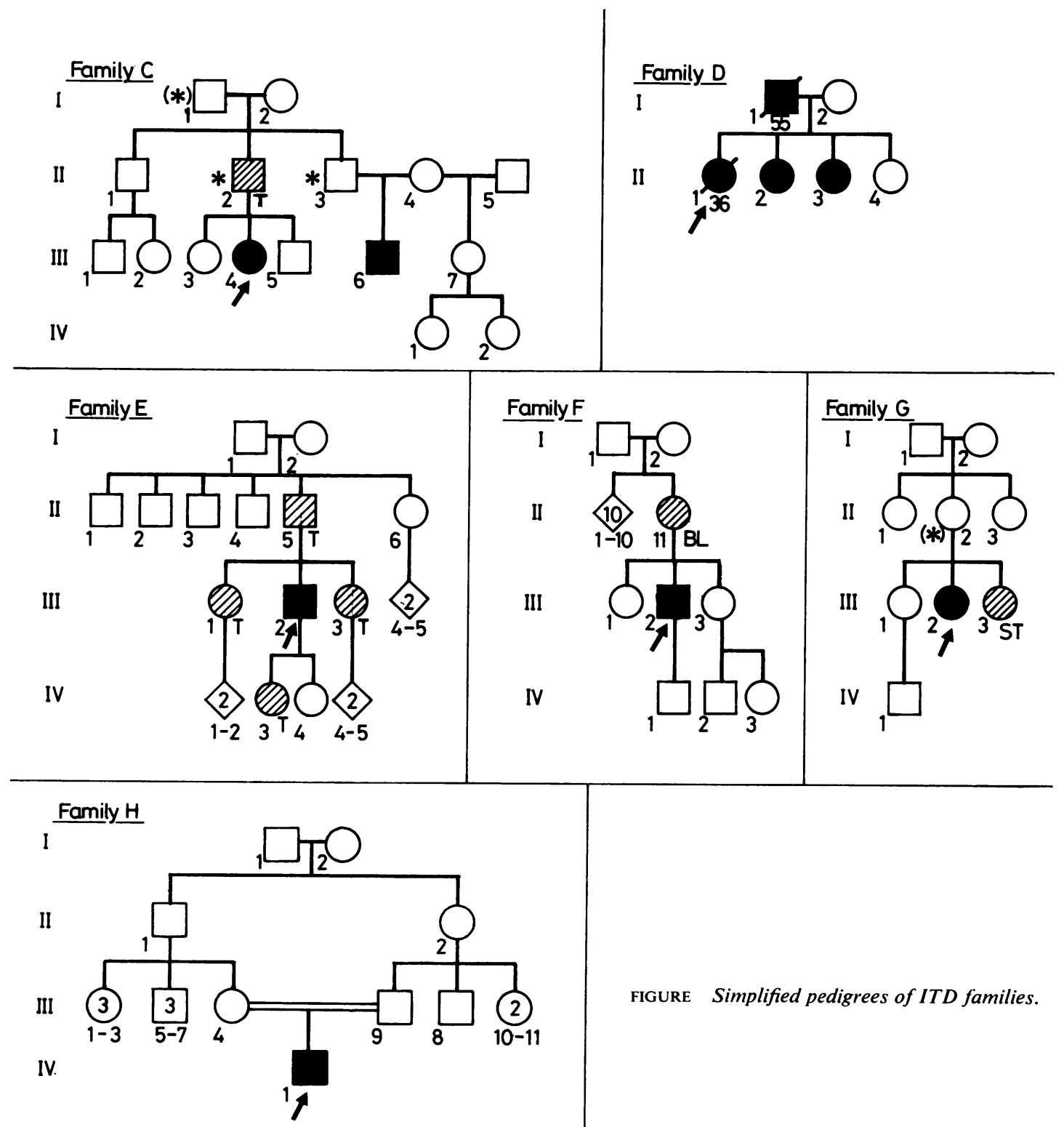

FIGURE Simplified pedigrees of ITD families. 
patients of Afro-Asian origin and the nine patients of European origin born during this interval.

The frequency of ITD in Israel between 1949 and 1959 (table 1), based on 11 Israeli-born patients, was 1:41 379 live births. For those of Afro-Asian origin born in this period the frequency was $1: 116980$ live births, while those of European origin had a frequency five times higher, 1:23 201 live births. Eight of the nine European cases had a father born in Eastern Europe (Russia, Poland, Rumania), and the frequency of ITD was 8:117 624 estimated births to fathers born in Eastern Europe or 1:14 703 estimated live births. These data on frequency of ITD in Israel permit the testing of various models of inheritance among patients of European origin. In the Afro-Asian group, the frequency was much lower and the small number of cases available made genetic analysis difficult. The following analyses were made, assuming ITD had the same mode of inheritance in all cases of European origin.

\section{$X$ LINKED INHER IT ANCE}

Since the number of affected females was not statistically different from the number of affected males ( 15 and 25 respectively) and a male transmitted the disease to his sons in family $\mathrm{A}$ (figure), $\mathrm{X}$ linked inheritance could not be the mode of inheritance in all cases.

\section{AUTOSOMAL RECESSIVE INHERITANCE}

If ITD among Jews were recessively inherited, the gene frequency would equal the square root of the observed frequency of the disease in the population*. ${ }^{13}$ Accordingly, the gene frequency $\mathrm{q}$ would be $1: 342(0.0029)$ in Afro-Asians, $1: 152(0.0066)$ in Europeans, and 1:121 (0.0083) in those with East European forebears.

In a recessive disorder, $25 \%$ of the offspring of

*This follows from the Hardy Weinberg formula: for random mating, if $p$ is the frequency of a dominant gene, and $q$ that of the recessive gene, the frequency of dominant homozygotes in the population is $\mathrm{p}^{2}$, that of recessive homozygotes is $\mathbf{q}^{2}$, and that of heterozygotes is $2 \mathrm{pq}$.

TABLE 1 Frequency of ITD by birthplace of mother in the Jewish population born in Israel (1949-1959).

\begin{tabular}{lcccc}
\hline Origin of mother & $\begin{array}{l}\text { Live births } \\
\text { 1949-1959 }\end{array}$ & $\begin{array}{l}\text { No of } \\
\text { affected }\end{array}$ & $\begin{array}{l}\text { Frequency of disease per } \\
\text { 106 live } \\
\text { births }\end{array}$ & $\begin{array}{l}\text { 1:live } \\
\text { births }\end{array}$ \\
\hline All origins & 455172 & 11 & $24 \cdot 2$ & $1: 41379$ \\
European* & 208807 & $9 \ddagger$ & $43 \cdot 1$ & $1: 23201$ \\
Afro-Asian $\dagger$ & 233961 & 2 & $8 \cdot 6$ & $1: 116980$ \\
\hline
\end{tabular}

*Includes mothers born in Europe or America, or in Israel with father born in Europe, America, or Israel.

Includes mothers born in Africa or Asia, or in Israel with father born in Africa or Asia

$\ddagger$ Previously we reported 10 ITD cases born in Israel in 1949-1959,11 but one of these cases was subsequently considered questionable and has been excluded in this paper. heterozygous parents who both carry the trait would $\mathbb{\Phi}$ be expected to show the disease. Not counting the $\stackrel{\mathbb{P}}{\rightarrow}$ affected proband in the sibship, there were 68 sibs $\Rightarrow$ with normal parents (of whom 59 were older than $20 \stackrel{\text { S }}{9}$ by 1980). None of these sibs was affected, whereas $\frac{1}{4}$, 을 or 17 , would be expected (14.75 if only those over 20 을 are considered). The differences between the zero $\frac{\bar{\sigma}}{\square}$ observed and the 17 (or even 14.75) expected is $\stackrel{\varnothing}{\varrho}$ highly significant. Thus, this test of the recessive model fails to support it. It must be recalled, how- $\overrightarrow{0}$

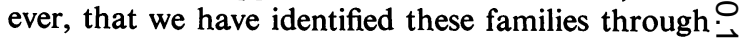
the affected sib, rather than through the supposedly $\vec{\omega}$ heterozygous parents. Correcting for the bias of ascertainment (Apert's method ${ }^{13}$ ), the expected number of affected sibs predicted by the recessive model is nine, which is still significantly different. $(p=0.001)$ from the zero observed (table 2).

In a recessively inherited rare disorder, if there $\vec{\omega}$ were no selection, the probability of a parent or an offspring of a patient being affected is approximately the gene frequency $\mathrm{q}$, for an aunt or uncle it is $\frac{1}{2} \mathrm{q}, \frac{\mathbb{D}}{\mathbb{Q}}$ and for first cousins it is $\frac{1}{4} q$. The expected number of $\frac{}{2}$ affected parents or offspring $\left(\mathrm{N}_{\mathrm{e}}\right)$ is the product of this probability and the total number of blood relatives. Table 3 shows that the expected number $\vec{\varphi}$ $\left(\mathrm{N}_{\mathrm{e}}\right)$ of affected parents, offspring, aunts and uncle $\& \stackrel{\infty}{\oplus}$ and cousins is much smaller than the observe number, $N_{0}$. To fit a recessive mode of inheritances the gene frequency would have to be considerab higher, a most unlikely eventuality in view of the completeness of our case finding.

Another test of the recessive model measures parental consanguinity. For a rare disorder, a high rate of consanguinity is predicted by a recessive model. The expected frequency of first cousin marriages among parents of affected subjects can be

TABLE 2 ITD among sibs of probands with ITD whose parents were unaffected Jews of European origin.

\begin{tabular}{llllll}
\hline $\begin{array}{l}\text { Sibship } \\
\text { size }^{*}\end{array}$ & $\begin{array}{l}\text { No of } \\
\text { sibships }\end{array}$ & $\begin{array}{l}\text { No of } \\
\text { sibs }\end{array}$ & $\begin{array}{l}\text { No of affected } \\
\text { Observed } \\
\left(N_{\mathrm{o}}\right)\end{array}$ & $\begin{array}{l}\text { Expected } \\
\left(N_{\mathrm{e}}\right)\end{array}$ & $\begin{array}{l}\text { Variance of } \\
\text { No of } \\
\text { affected }\end{array}$ \\
\hline 1 & 6 & 6 & 6 & $6 \cdot 00$ & $0 \cdot 000$ \\
2 & 6 & 12 & 6 & $6 \cdot 86$ & $0 \cdot 732$ \\
3 & 8 & 24 & 8 & $10 \cdot 38$ & $2 \cdot 104$ \\
4 & 5 & 20 & 5 & $7 \cdot 31$ & $2 \cdot 100$ \\
5 & 0 & 0 & 0 & $0 \cdot 00$ & $0 \cdot 000$ \\
6 & 2 & 12 & 2 & $3 \cdot 65$ & $1 \cdot 552$ \\
7 & 2 & 14 & 2 & $4 \cdot 04$ & $1 \cdot 940$ \\
Total & 29 & 87 & 29 & $38 \cdot 24$ & $\begin{array}{l}8 \cdot 428 \\
\text { (SD }=2.90)\end{array}$ \\
\hline
\end{tabular}

*Includes the proband.

The numbers given exclude sibs who died before the age of 20 or had not reached 20 by 1980 . This exclusion did not appreciably alter the results.

$\mathrm{N}_{\mathrm{e}}=$ expected number under the recessive hypothesis.

$\mathrm{N}_{0}=$ observed number.

$\mathrm{N}_{\mathrm{e}}-\mathrm{N}_{\mathrm{o}}=9 \cdot 24=3 \cdot 19 \times \mathrm{SD}$. 
TABLE 3 Evaluation of the recessive model of ITD: patients with ITD by relationship to proband (Israeli Jews of European origin).

\begin{tabular}{lcll}
\hline $\begin{array}{l}\text { Relationship } \\
\text { to proband }\end{array}$ & \begin{tabular}{l} 
Total No \\
\cline { 2 - 4 }
\end{tabular} & $\begin{array}{l}\text { No of affected } \\
\text { Observed } \\
\left(N_{\mathrm{o}}\right)\end{array}$ & $\begin{array}{l}\text { Expected } \\
\left(N_{\mathrm{e}}\right)\end{array}$ \\
\hline Parents & 72 & 2 & $\mathrm{q} \times \mathrm{N}=0.47$ \\
Offspring & 19 & 6 & $\mathrm{qxN}=0 \cdot 12$ \\
I'ncles and aunts & 189 & 1 & $\frac{1}{2} \mathrm{q} \times \mathrm{N}=0.62$ \\
Cousins & 181 & 2 & $4 \mathrm{qxN}=0.30$ \\
Total & 461 & 11 & $1 \cdot 51$ \\
\hline
\end{tabular}

$\mathrm{N}$ - excludes those under the age of 20 by 1980 or dead before 20 . $\mathrm{N}_{\mathrm{e}}=$ expected under an autosomal recessive model.

$q=$ ITD gene freiluency in the hyopthesis of a recessive inheritance (1:152). In families $A$ and $D$, three sibs in each were affected. The number of parents was therefore reduced from 80 to 72 . Where two cousins were affected, only the cousins of the proband were counted.

calculated if the frequency of first cousin marriages in the population and the frequency of the recessive allele are known*.13 Using the reported rate of consanguinity in the Israeli European population of about $2 \%$ and a gene frequency of 0.0066 , the expected proportion of affected from first cousin marriages would be $18 \%$. Among the 32 parent sets of affected subjects for whom the pedigree was known, there was only one consanguineous set, a cousin-cousin marriage (figure, family $\mathbf{H}$ ). Thus, the proportion of consanguineous sets was only $3 \%$, which was not significantly different from the consanguinity rate in the general population. The gene frequency would have to be about six times higher than was observed to account for the consanguinity rate in our cases if a recessive inheritance model were valid for ITD.

The wide discrepancy between predictions based on a recessive model and the observed data makes it most difficult to accept the conclusion of Eldridge and associates $^{8}$ that ITD in European Jews is recessive.

\section{AUTOSOMAL DOMINANT INHERITANCE}

An alternative possibility is that ITD is dominantly inherited. Assuming complete penetrance, one parent of each patient would be affected. In order to eliminate possible new mutants, ascertainment of obligatory gene carriers among forebears of the patients can be based only on an affected parent, a non-affected parent with at least two affected offspring, or a non-affected parent with affected collaterals or forebears who produced an affected child or other progeny.

${ }^{*} \mathrm{k}=\frac{\mathrm{c}(1+15 \mathrm{q})}{16 \mathrm{q}+\mathrm{c}(1-\mathrm{q})}$ where $\mathrm{k}$ is the expected frequency of parental first cousin marriages among parents of cases, $c$ is the frequency of first cousin marriages in the general population, and $q$ is the frequency of the recessive allele.
These restrictions limited us to an analysis of forebears of the ITD patients among familial cases. An autosomal dominant model requires that 11 persons (marked by asterisks in the figure) were obligatory gene carriers, but were asymptomatic. Since none of the oldest generations was examined, we limited the analysis to the first generation where a case was observed and to the following generations.

In autosomal dominant inheritance, $50 \%$ of offspring and of sibs of cases or of asymptomatic carriers are at risk of being affected. In order to eliminate possible new mutations, only the sibs of the familial cases were considered but the offspring of both familial and isolated cases were counted. In all cases, only those subjects who had reached 20 years of age by 1980 were considered.

Looking at the parents, sibs, and offspring of the cases and the asymptomatic carriers of the tested generations, at least 27.5 persons would be expected to show ITD according to an autosomal dominant model, but only 14 were found. Thus, the penetrance was only $51 \%$.

Variable expression of a dominant gene may be occurring, producing 'formes frustes' of ITD (figure). In family $E$ tremor appeared in three successive generations: the father of the proband had a severe tremor of the head and hands and the proband's two sisters had tremor of the hands, as did one of his two daughters. In family $F$ the mother of the proband had blepharospasm. She died of a myocardial infarction before she could be examined. In family $G$ the sister of the proband stammered when emotionally upset. In family B and family C stammering and tremor respectively were found as well. Also a maternal uncle of an 'isolated' case was reported to have died with 'scoliosis', which could have been dystonic posture. ${ }^{3}$ If all these cases were 'formes frustes' of ITD, there would be 27 affected subjects with an expected number of $39 \cdot 5$, raising the penetrance to $68 \%$.

For a dominant model, the gene frequency is approximately equal to one-half the observed frequency of the trait in the population*, which should in addition be corrected for penetrance. The observed frequency of ITD was 1:22 775 live births. Accepting $68 \%$ penetrance, the gene frequency would be $1: 30974(0.00003)$; accepting $51 \%$, it would be $1: 23230(0 \cdot 00004)$. The data in our study would be compatible with an autosomal dominant model where the gene frequency would be 3 to $4: 100000$.

* This prediction is also based on the Hardy Weinberg formula. For dominant inheritance, the frequency of the carriers is $2 q p+p^{2}$. For a rare disease (that is, where $p$ is very small) the frequency of carriers is approximately equal to $2 \mathrm{p}$ and the gene frequency is about half the carrier frequency. 


\section{Alternative hypotheses}

MULT IFACT ORIAL INHERIT ANCE

The simple model presented above of a monogenic autosomal dominant inheritance with low penetrance is impossible to distinguish at present from a more complex model such as multifactorial inheritance. The rationale for this statement will be developed in a future report.

\section{MUTATIONS}

If the ITD gene has a high mutation rate, isolated cases might represent new mutations. There were four isolated cases born in Israel between 1949 and 1959 among 208807 live births. The mutation rate per gamete would be $4:(2 \times 208807)$ or $1: 104404$ gametes. Assuming $60 \%$ penetrance, the mutation rate would be about 1:63000 gametes. On the other hand, it is known that the mutation rate for most genes increases with parental age. ${ }^{13}$ An expected maternal and paternal age was computed for the Israeli isolated ITD patients of European origin, born from 1947 onwards, using census data on the general population of Israel, data on average age of mothers by parity of children, and information on median age of brides and grooms. ${ }^{12}$ While the mean observed maternal age ( 25.8 years) did not differ significantly from expected ( 25.2 years), the mean observed paternal age ( 33.8 years) was significantly higher than expected ( 30.1 years) ( $U$ and $t$ tests: $\mathrm{p}=0.01)$. The paternal-maternal age difference (8 years) was also significantly increased in our cases compared to the general population (4.7 years) ( $\mathrm{p}=0.05, t$ test; $\mathrm{p}=0.07$, $\mathrm{U}$ test). Thus, while it is possible that some of the isolated ITD cases are actually examples of new mutations, the rate of mutation would have to be very high to account for the large number of isolated cases. Moreover, against this possibility is the non-homogeneous ethnic distribution of ITD, that is, the relatively greater frequency among Jews of European (especially Eastern European) origin as compared to Jews of Afro-Asian origin and Arabs.

\section{PHENOCOPIES}

Some cases of 'torsion dystonia' may represent phenocopies or even other genetic diseases. ${ }^{15}$ In contrast to cases resulting from mutation, phenocopies are not genetically determined and would not be transmitted to offspring of the affected. Therefore, only the examination of the children of affected subjects considered so far as 'isolated' could distinguish between phenocopies and mutations. Until 1982, none of the 21 children of the isolated patients showed signs of ITD, but only seven children had reached 20 years of age. It is still possible, therefore, that some of the children will develop ITD.

\section{Discussion}

The present paper represents the most detailed effort $\stackrel{\mathbb{\Phi}}{=}$ to date to identify the mode of inheritance of ITD. $\overrightarrow{\vec{G}}$ By combining a thorough, population-wide search $\stackrel{9}{\rightarrow}$ for ITD cases with precise data on live births available in Israel, calculation of disease frequency $\frac{\bar{\sigma}}{\bar{s}}$ achieved an accuracy which had not previously been $\frac{\vec{\sigma}}{\Phi}$ possible. The concentration of cases of ITD among $\varrho$ Jews, ${ }^{\mathbf{5}}$ especially those with Eastern European forebears, which was primarily suspected on the $\overrightarrow{0}$ basis of incomplete information and tentative estimates, ${ }^{8}$ was conclusively verified in our study. In $\vec{\omega}$ the general Israeli population almost equal numbers of Jews of European and of Afro-Asian origin were available for study, and ITD was found to be concentrated with five-fold greater frequency among Europeans (eight-fold among Eastern Europeans). $\vec{\omega}$ Among Arabs, ITD was apparently uncommon.

Given accurate data on frequency, it was possible to calculate gene frequency and test various models $\vec{T}$ of inheritance of ITD. Our material consisted of two $\mathbb{D}$ groups: familial cases, all of which occurred in subjects of East European origin, and isolated cases. The latter included European and Afro-Asian $\rightarrow$ subjects as well as a Druze Arab. We recognise the possibility that heterogeneity or even phenocopigs. may exist and appear clinically similar, if not identical, to each other. However, for purposes this analysis, we assumed that all European case $\frac{\overrightarrow{\mathrm{e}}}{\overline{0}}$ were inherited in the same way.

Since the sex ratio among the affected was not $\stackrel{\circ}{\otimes}$ significantly different from unity, and a father and $\overrightarrow{\vec{F}}$ son were affected in one family, an X linked inheri-윽 tance model was rejected. The simple autosomal recessive model for ITD, advocated in recent yearso by Eldridge and associates, ${ }^{8}$ was tested in several ways. The first and most powerful test involved aç search for affected sibs born to clinically normaloparents. A second test involved goodness-of-fit between the frequency of affected blood relatives $ᄋ$ observed and expected. A third test involved estimation of consanguinity rate which should have been음 increased among parents of affected subjects since ${ }_{D}$ the trait is rare. None of these tests was consistent음 with recessive inheritance for all the European Jewish cases.

The last two tests were based on the observed N frequency in patients per million live births in Israel స్ట between the years 1949 and 1959. Among those borno in this interval, some new ITD cases may yet develop since not all subjects in each family had passed the $\frac{\bar{\Phi}}{\mathbb{D}}$ age of risk. However, one would have to postulate a disease frequency many times higher than observed 0 in the present study to consider an autosomalo recessive model likely. The completeness of case 
finding in Israel makes a large underestimate of true frequency very unlikely. Incomplete case finding could theoretically explain the paucity of affected sibs. However, the observed number of cases in parents, offspring, cousins, aunts, and uncles was higher than expected in a simple recessive model, so that incomplete case finding can be discounted as an explanation of the small number of affected sibs.

We tried to salvage the recessive model by considering the possibility of variable expression of the ITD gene. If blepharospasm, tremor, scoliosis, and stammering were 'formes frustes', their inclusion added a sib in family B and another in family C, as well as a daughter, two sisters, and a father of a proband in family E. A mother of a proband would be added in family $\mathrm{C}$ and a sister of a proband would be added in family G. However, the discrepancy from expectation in the recessive model was increased, since the number of relatives of affected, which was already too large for recessive inheritance to be correct, would be made still larger. Moreover, addition of 'formes frustes' in family $E$ resulted in ITD in three successive generations, a most improbable event in the recessive inheritance of a rare disorder. Also, in families $\mathrm{C}$ and $\mathrm{F}$, two successive generations would be considered affected.

An autosomal dominant model could not be rejected. It seemed to account well for the occurrence of ITD in at least two of the four families with more than two affected subjects (families A and D plus three other families if the 'formes frustes' were accepted as ITD). Dominant inheritance could explain our data, assuming a low penetrance of $51 \%$ (or $68 \%$ if 'formes frustes' were included).

Multifactorial inheritance of the ITD phenotype requiring the presence of two or more genes could also not be rejected. All cases are unlikely to be the result of mutations, since the mutation rate would have to be very high, and we would have difficulty accounting for the concentration of cases in Jews of European (especially East European) origin, independent of their place of birth. However, since the mean age of the patients' fathers was found to be higher than the average age of fathers in the general population, and the mutation rate is correlated with parental age, at least some isolated cases might be the result of mutation. Bundey et al ${ }^{16}{ }^{17}$ also observed a higher paternal age of their isolated cases of ITD who were non-Jews.

We cannot yet exclude the possibility that not all cases of ITD fit the same genetic model and heterogeneity may be present. Collection of more pedigrees with more rigorous study of allegedly 'normal' relatives will increase our understanding of the genetics of ITD. Of course, if a biochemical abnormality were found, it would greatly simplify the classification of patients currently classified on clinical grounds alone. Discovery of a biochemical marker would also facilitate genetic linkage studies. The small number of familial cases available in Israel and the very large number of known genetic traits which would have to be tested combine to make linkage studies unfeasible at present.

Finally, a question arises as to why the disease is more common among Ashkenazi Jews than in other populations. An unusually high penetrance is unlikely since our figures of penetrance are similar to those of Zeman and Dyken for non-Jews. ${ }^{3}$ Assuming all sporadic cases were new mutations, the mutation rate in European Jews would be 1:104000 to $1: 63000$ gametes, which is much higher than the mutation rate of $1: 3000000$ to $1: 500000$ calculated by Zeman and Dyken ${ }^{3}$ and based on non-Jews plus one Jewish family. But both their values and ours are too crude for definitive conclusions to be drawn. Moreover, if a higher mutation rate or a higher proportion of phenocopies existed among Ashkenazi Jews, the proportion of isolated cases among Jews should also be higher. From the data of Zeman and Dyken, ${ }^{3} 50$ of 70 cases $(71.4 \%)$ were isolated cases in Jews and 31 of $44(70.5 \%)$ in non-Jews. In Israel, 22 of $26(84.6 \%)$ were isolated, which is not significantly different. Although the ITD gene is believed to be associated with high intelligence, ${ }^{518}$ there is no good evidence that higher intelligence exerts a favourable selective pressure, and certainly not enough to account for the concentration of the ITD trait in Ashkenazi Jews of East European origin. Genetic drift may be a more acceptable answer. We can only speculate on the correct explanation at this time.

This work was supported in part by the IsraelUnited States Binational Science Foundation and by a grant from the Chief Scientist, Israel Ministry of Health. Dr Zilber, on leave from Laboratoire de Neurobiologie Cellulaire, Gif-sur-Yvette, France, received support from the Centre National de la Recherche Scientifique, France.

\section{References}

1 Johnson W, Schwartz G, Barbeau A. Studies on dystonia musculorum deformans. Arch Neurol 1962;7:301-13.

2 Larsson T. Sjögren T. Dystonia musculorum deformans: a genetic and clinical population study of 121 cases. Acta Neurol Scand 1966;42:suppl 17.

: Zeman W, Dyken P. Dystonia musculorum deformans; clinical, genetic and pathoanatomical studies. Psychiatr Neurol Neurochir 1967;70:77-121.

1 Eldridge R, Harlan A, Cooper IS, Riklan M. The hereditary torsion dystonias (dystonia musculorum deformans): geographical distribution and IQ in dominant and recessive forms. Trans Am Neurol Assoc 1969;94: 248-50. 
5 Eldridge $\mathbf{R}$. The torsion dystonias: literature review on genetic and clinical studies (dystonia musculorum deformans). Neurology (Minneap) 1970;20:1-78.

- Eldridge R, Koerber T. The torsion dystonias: some genetic and psychiatric implications. Psychiatric Forum $1971 ; 3: 27-33$.

7 Eldridge R, Gottlieb R. The primary hereditary dystonias: genetic classification of $\mathbf{7 6 8}$ families and revised estimate of gene frequency, autosomal recessive form and selected bibliography. Adv Neurol 1976;14:457-73.

8 Eldridge $R$, Koerber $T$. Torsion dystonia: autosomal recessive form. In: Goodman RM, Motulsky AG, eds. Genetic diseases among Jews. New York: Raven Press, 1979:231-51.

- Korczyn AD, Zilber N, Kahana E, Alter M. Inheritance of torsion dystonia. Reply. Ann Neurol 1981;10:204-5.

10 Alter M, Kahana E, Feldman S. Differences in torsion dystonia among Israeli ethnic groups. Adv Neurol 1976;14:115-20.

11 Korczyn AD, Kahana E, Zilber N, Streifler M, Carasso R, Alter M. Torsion dystonia in Israel. Ann Neurol 1980;8: 387-91.

12 Statistical Abstract of Israel Nos 1-17. Central Bureau of Statistics, Jerusalem, The Government Printer, 1950-1966; and personal communication from the Israel Central@ Bureau of Statistics.

13 McKusick VA. Human genetics. Englewood Cliffs, NJ: Prentice-Hall, 1969.

14 Goldschmidt E, Ronen A. The rate of consanguinity in $\stackrel{\vec{P}}{\rightarrow}$ the communities of Israel. Bull Res Counc Israel (Exp MJ)음 1956;58:317-8.

15 Goldman JE, Katz D, Rapin I, Purpura DP, Suzuki K. $\frac{\bar{\sigma}}{\bar{\omega}}$ Chronic $G_{M_{1}}$ gangliosidosis presenting as dystonia. I. Clinical and pathological features. Ann Neurol $1981 ; 9: \AA$ 465-75.

16 Bundey S, Harrison MJG, Marsden CD. A genetic study of torsion dystonia. J Med Genet 1975;12:12-9.

17 Bundey S, Harrison MJG, Marsden CD. Paternal age effect in isolated juvenile torsion dystonia. Adv Neuro $\vec{\omega}$ 1976;14:153-5.

18 Riklan M, Cullinan T, Cooper IS. Psychological studies in dystonia musculorum deformans. Adv Neurol 1976; 14:189-200.

Correspondence and requests for reprints to Professor A D Korczyn, Department of Physiology $\vec{\omega}$ and Pharmacology, Sackler School of Medicine,o Tel Aviv University, Ramat Aviv, Israel. 